\title{
Modern problems of energy security of the Caspian regions of Russia and Azerbaijan
}

\author{
S.M. Senderov ${ }^{1}$, N.A. Yusifbeyli ${ }^{2}$, V.I. Rabchuk ${ }^{1}$, A.M. Huseynov ${ }^{3}$, V.Kh. Nasibov $^{3}$, G.B. Guliyev ${ }^{3}$, \\ S.V. Vorobev ${ }^{1 *}$, E.M. Smirnova ${ }^{1}$ \\ ${ }^{1}$ Melentiev Energy Systems Institute, Russia \\ ${ }^{2}$ Azerbaijan Republic State Agency on Alternative and Renewable Energy Sources \\ ${ }^{3}$ Azerbaijani Scientific - Research and Designed-Prospecting Institute of Energetics
}

\begin{abstract}
The article is devoted to the analysis of the problems of ensuring the energy security of the Caspian regions of Russia and the Republic of Azerbaijan. The priority problems of energy security analysis were raised at the regional level and at the level of countries as a whole. It describes the main indicators of energy security, the monitoring of which is relevant for both countries. The article analyses the main factors changing the situation in both countries in the medium term and draws conclusions on the direction of the main actions so that the situation changes for the better.
\end{abstract}

\section{Introduction}

In terms of ensuring energy security at the general state level, Russia and Azerbaijan combine features of the requirements for such a security system. For both countries, these requirements are mainly related to the need for a sufficient supply of their domestic consumers with the required types of energy resources from their own sources of these resources, as well as with the need to supply oil and gas for export in reasonable amounts. However, with the transition to the regional level and, in particular, to the level of the Caspian regions of these countries, the specifics of the power supply requirements of these regions for Azerbaijan and Russia differ sharply. These differences are caused by the different significance of the Caspian regions in terms of ensuring the energy security of both countries at the national level. If for Azerbaijan such significance of its Caspian region is absolute, then for Russia this significance is much lower.

All volumes of oil and gas produced in Azerbaijan fall in the Caspian regions (including offshore hydrocarbon deposits of this country in the Caspian Sea). The total share of all primary fuel and energy resources received here today is more than 95\% [1] of the total volume of these resources produced in the country. With that said, for Azerbaijan it is necessary to talk about regional threats to energy security of national importance.

Unlike the Caspian regions of Azerbaijan, the share of Russian Caspian regions in the total volume of primary energy resources produced in the country is just over $1 \%$ (natural gas produced in the regions and electricity generated at wind power plants in Kalmykia and hydroelectric power plants in Dagestan). At the same time, these regions themselves have their own problems with ensuring energy security. These specific problems will be discussed below together with a review of the overall situation with the provision of the energy sector of Azerbaijan and in the Caspian regions of Russia.

Before considering the problems of regional significance with ensuring the energy security of the Caspian regions of both countries, we first consider regional problems of national importance. For the reasons mentioned above, we consider these problems only for Azerbaijan.

\section{2 the main threats to the energy security of national importance in the Caspian regions of Azerbaijan and the current scale of their implementation}

For clarity, let us consider the problems of national importance with ensuring the energy security of the Caspian regions of Azerbaijan through the real scale of the implementation here of the most important threats to energy security in recent years.

The considered threats to energy security relate to the situation with the development and functioning of the oil and gas sector of the Caspian region of Azerbaijan. Before considering the threats to the energy security of national importance, consider the main indicators of the oil and gas sector in Azerbaijan.

Azerbaijan has a large number of oil and gas fields and prospective structures in the Caspian Sea. The proven oil reserves in Azerbaijan amount to 7 billion

Corresponding author: seregavorobev@isem.irk.ru 
barrels, natural gas 2.6 trillion. m3. The predicted values of oil reserves -10 billion barrels, natural gas - 3 trillion $\mathrm{m}^{3}$. Among the Caspian fields, the most significant is the Azeri-Chirag-Gunashli (ACG) oil and gas field, whose proven oil reserves are estimated at 1.2 billion tons, gas 360 billion $\mathrm{m}^{3}$ [2].

Another large field is gas condensate - Shah Deniz, whose reserves are estimated at 1.2 trillion. $\mathrm{m}^{3}$. According to forecasts at the second stage of this field, gas production can be increased to 24 billion $\mathrm{m}^{3}$ per year. Another 600 billion $\mathrm{m}^{3}$ of gas - in such fields as Absheron, Umid, Ashrafi, Karabakh. In addition to the above fields, there are five more promising structures with a total stock of 2.2 trillion. $\mathrm{m}^{3}$ of gas (Babek - 400 billion $\mathrm{m}^{3}$, Nakhchivan - 300 billion $\mathrm{m}^{3}$, Zafer-Mashal 300 billion $\mathrm{m}^{3}$, Araz-Alov-Sharg - 700 billion $\mathrm{m}^{3}$ and Shafag-Asiman - 500 billion $\mathrm{m}^{3}$ ).

The development of oil and gas fields in the Caspian became possible after the signing in 1994 of the "Contract of the Century" [3] and the subsequent inflow of large investments. The project participants were 13 companies, including such as BP (35.8\%), SOCAR (11.6\%), Chevron (11.3\%), Statoil (8.6\%), and others. After signing the "Contract of the Century" 26 agreements were signed with 41 oil companies from 19 countries.

Since 1997, within 20 years, 460 million tons of oil and 140 billion $\mathrm{m}^{3}$ of gas have been extracted from the ACG.

For the implementation of large oil and gas fields were built or reconstructed pipelines:

Baku-Tbilisi-Ceyhan (oil - to the Mediterranean Sea), Baku-Supsa (oil - to the Black Sea), Baku-Erzurum (gas pipeline), Baku-Novorossiysk (oil).

In 2018, the construction of three important components of the Southern Gas Corridor was completed:

Shah Deniz-2, South Caucasus gas pipeline (through Georgia) and TANAP (gas transportation to Turkey).

By 2020, construction of the TAP gas pipeline with a length of $878 \mathrm{~km}$ will be completed, as a continuation of the TANAP gas pipeline to Europe (Greece - $550 \mathrm{~km}$, Albania - 215 km, Italy - 8 km).

By 2020, the length of export gas pipelines to Europe in single-line terms will be $3,500 \mathrm{~km}$. The capacity of TANAP is 16 billion $\mathrm{m}^{3}$ (to Turkey -6 billion $\mathrm{m}^{3}$ ), (to Europe - 10 billion $\mathrm{m}^{3}$ ).

The analysis of the operating conditions of the oil and gas sector revealed the most significant threats to the energy security of Azerbaijan, the implementation of which can lead to problems in ensuring not only energy but also economic security. Among the most significant threats are:

- reduction of oil production in the region;

- decrease in the export of hydrocarbon resources.

Each threat must be considered taking into account the mutual influence of internal and external risks and survivability (in the English-language literature, risk and resilience).

Reduction in annual oil production in the Caspian region of Azerbaijan from 2010 to 2017 amounted to about 23\% (from 50.8 to 38.8 million tons) [1], mainly due to the steady narrowing of the resource base. The main deposits of liquid hydrocarbons in the region are located in the Baku oil and gas region (Apsheron Peninsula) and in the Apsheron-Pribalkhash zone of the deep-water shelf of the Caspian Sea - a powerful oil structure of ACG (Azeri-Chirag-Gunashli oil-bearing areas). On the Absheron Peninsula, oil has been produced for more than 150 years. The peak of its production here has long been passed and the primacy in the volume of production of liquid hydrocarbons in the Caspian region of Azerbaijan at the beginning of the 21st century passes to the shelf zone indicated above.

Today, $75 \%$ of the volume of oil from the Caspian region (and in Azerbaijan as a whole) is produced in the ACG areas. The remaining $25 \%$ comes from the old fields of the Baku region and the relatively small fields of the shallow shelf of the Caspian Sea (Oil Rocks, Mud Creek, O. Sandy, etc.).

After the peak of production in 2010, a continuous decline in the production of oil began at the ACG (2-5\% per year). This reduction in production occurs for a number of reasons. The main reason that can be called global is the lack of an agreement among the Caspian states (Russia, Iran, Azerbaijan, Turkmenistan and Kazakhstan) to obtain a clear, legally verified document on the division of the Caspian Sea between these countries. If such a document were available, it would be possible to further increase production at the ACG oil complex (in case of successful supplementary exploration of the eastern areas of this complex and their commissioning). Numerous studies show that there is oil in these eastern areas, but the mentioned exploration without the above document is impossible because of the disagreement of Turkmenistan. As a result, the cost of oil production in the existing areas began to grow (the flow rates of wells are falling, their number has to be increased). Thus, in 2008, the cost of oil produced here and delivered to the port of Ceyhan was estimated at $\$$ 7.5 / bbl., and today it is close to \$ 15 / bbl.

The real drop in the level of oil production in the deep-water shelf of the Caspian Sea is accompanied by the realization of two more threats to the energy security of Azerbaijan. This is a decrease in the export of hydrocarbon resources and deterioration in the situation with investments in the oil and gas sector of the country.

The decline in oil production is 23\% from 2010 to 2017. and a slight reduction in gas production at a virtually unchanged level of domestic consumption of primary energy resources in the country naturally reduced the export of hydrocarbon resources both in physical and monetary terms, although over this period the share of the oil and gas sector of the Caspian regions in the country's export potential decreased slightly. If in 2011 the volume of total exports of Azerbaijan was approximately \$26.6 billion, and oil and gas exports amounted to about $\$ 25.1$ billion, which corresponded to $94.5 \%$. Already in 2016, the volume of total exports of Azerbaijan amounted to approximately 9.1 billion US dollars, while oil and gas exports amounted to approximately 8 billion US dollars, which corresponded to $87.4 \%$ [4]. 
If the decrease in exports of Azerbaijani hydrocarbons in physical terms was only $21.8 \%-59$ billion tons of fuel equivalent in 2016 it was 75 billion tons of fuel equivalent. in 2010 [1], the decrease in "monetary" exports was several times greater compared to 2011 in 2016, "monetary" exports of the country decreased by 2.9 times, and oil and gas exports by 3.14 times. This situation has developed due to the large difference in world prices for hydrocarbons in 2010 and in 2016.

Naturally, with a decrease in exports of Azerbaijani hydrocarbons, the situation with investments in the economy, including in the oil and gas sector of the country, is deteriorating, while the volume of foreign investment compared to domestic investment has decreased slightly. The maximum annual volumes of foreign investment since the beginning of the implementation of the Contract of the Century fell on 2014, when USD 11,697.7 million was invested in the economy of Azerbaijan. Already in 2017, the volume of foreign investment decreased by $22 \%$ and amounted to $\$$ 9,120.5 million. During the period under review, total investments in the economy of Azerbaijan have decreased by approximately two times. So, if in 2014, total investments amounted to $\$ 27,907.5$ million, then in 2017, \$ 13,851.2 million was invested. Indicators on domestic investment have deteriorated significantly in recent years, so in 2016, these investments compared to 2014 decreased by almost 4 times and amounted to US \$ 4,730.7 million. As for investments in the oil and gas sector of Azerbaijan, the decline in investment here compared to the non-oil sector is small. If the volume of foreign investments in the oil sector of Azerbaijan in 2014 was approximately 6,730.7 million US dollars, over the same 2016 this figure decreased by about 27\% and amounted to 4,900.8 million US dollars. This decrease in investment is mainly due to the practical completion of capital works within infrastructure projects, for example, in 2018, the construction of three important components of the South Gas Corridor was completed.

Analysis of the scale of implementation of threats to energy security of the national significance of the Caspian region of Azerbaijan showed that the overall situation in the country's economy and the level of its energy security is almost entirely determined by the situation with the development and functioning of the oil and gas sector in this region.

The above were considered threats to energy security, and then we will consider the vitality of the energy sector in relation to the overall state of energy security in general and in relation to each of the threats.

It should be noted that at the present time in the Republic of Azerbaijan all the requirements for the main energy resources are provided by internal sources. This situation should continue in the foreseeable future. Thus, from the standpoint of reliability of fuel and energy supply, it can be stated that, in general, the situation in the Republic of Azerbaijan is assessed positively.

All the threats to energy security mentioned above relate to the foreign economic activity of the energy sector, and therefore the degree of their implementation is mainly determined by external conditions, primarily the price of oil. It should be noted, following the devaluation of the Azerbaijani manat in 2015, 2016 was the worst year in economic terms in the last ten years, due to the fact that the price of oil decreased more than three times, and, accordingly, the flow of currency from hydrocarbon exports decreased.

With the increase in oil prices, 2017 has become a year of stabilization in the economy. From the beginning of 2018, real growth in the economy is noticeable. In the first quarter, Azerbaijan's economy grew by $2.3 \%$, while growth in the non-oil sector was about $3 \%$, industrial production increased by $2 \%$, and non-oil industry - by about $10 \%$. During the first quarter, investments in the amount of $\$ 3.5$ billion were invested in the country's economy, with a significant part of them being foreign investments.

Foreign exchange reserves increased by $\$ 2.2$ billion and are now equal to $\$ 44.2$ billion, foreign trade turnover grew by $31 \%$, non-oil exports increased by $37 \%$, and total exports grew by $24 \%$.

In 2017, a new agreement was signed in Baku (extension of the "Contract of the Century") on the development of the ACG block until 2049 with the share participation of BP companies - 30.37\%, SOCAR - 25\%, Chevron - 9.57\%, INPEX - 9 , 31\%, Equinor - 7.27\%, Exxon Mobil - 6.79\%, etc.

At the 5th meeting on 12.08.2018 in Aktau, the "Convention on the Legal Status of the Caspian Sea" was adopted. This meeting did not address the issue of dividing the bottom of the Caspian Sea between the five countries Russia-Turkmenistan-Azerbaijan-KazakhstanIran. The issue will be resolved in a mutual discussion between countries based on the International Agreement. Despite the unresolved issue of dividing the bottom of the Caspian Sea in the first quarter, as part of the new agreement (extension of the Contract of Century) for the development of the ACG block, Azerbaijan received a \$ 450 million bonus, which indicates the attractiveness of the Azeri-Chirag -Gunashli " for leading foreign oil and gas companies. It is expected that within the framework of the new agreement for 32 years 40 billion US dollars will be invested in the economy of Azerbaijan and 3 billion barrels of oil will be produced. Thus, the oil and gas sector of Azerbaijan will develop steadily in the foreseeable future, and an agreement on dividing the bottom of the Caspian Sea will only increase the opportunities for additional growth in the oil and gas sector of Azerbaijan.

Despite the recovering positive trends in the oil and gas sector, the economic and energy security of Azerbaijan is determined and will be determined mainly by world prices for hydrocarbons. To reduce the economy's dependence on external factors (oil price), on December 6, 2016, the President of Azerbaijan signed 13 documents on creating the ideological basis for the development of the Azerbaijan Republic for short, medium and long-term periods, where the main leitmotif of development envisages diversification of the economy, reducing the share of the oil sector by accelerated development of the non-oil sector of the economy. Therefore, when considering the energy 
security of Azerbaijan, the main focus is on electricity security, which will be discussed below.

\section{The situation with energy security of the Caspian regions Azerbaijan and Russia}

To assess this situation, it seems advisable to use the methodology for assessing the state of the region's energy security [5], developed at Melentiev Energy Systems Institute. In the case of a specific region, the methodology assumes the mandatory consideration of this situation by such analysis objects as:

- the ability to meet the needs of the region in the main types of energy resources with an appropriate analysis of the possibilities of covering the maximum electrical load in the region;

- own capabilities of the region to meet its needs for primary energy;

- the share of the dominant resource in the consumption of primary energy in case of an emergency decrease in the supply of this resource;

- share of the largest source in the production of electricity in the region;

- the ability to meet the peak of the growing demand for energy resources in conditions of significant cooling in the region;

- the state of the basic production assets of the energy sectors of the region, including the situation with the renewal of the production assets of the electric power industry, as an infrastructure sector.

According to the mentioned methodology, the scale and dynamics of changes in the situation for a particular object of analysis are estimated in the analysed period by the ratio of the numerical value of the corresponding indicator with specially defined and justified threshold values of this indicator. Thresholds in this case denote the threshold of transition of the current value of the indicator into various qualitative states of this indicator: acceptable, pre-crisis, crisis. Knowing the quality of all indicators of regional energy security and using a specially developed apparatus for assessing the relative importance of indicators, it is possible to get some kind of integral assessment of the situation with ensuring energy security in the region. The list of recommended indicators for use in this case is as follows:

- the ratio of the total available power of sources of electricity in the region to the maximum electrical load of consumers in its territory;

- the ratio of the sum of the available power of the power plants and the transmission capacity of the intersystem connections of the region to the maximum electrical load of consumers in the region;

- the ability to meet the primary energy needs from the region's own sources;

- the share of the dominant resource in the total primary energy consumption in the region;

- the share of the largest power plant in the installed electrical capacity of the region;
- the level of potential supply of demand for fuel in the conditions of a $10 \%$ increase due to the cooling in the region;

- degree of depreciation of the basic production assets of the energy sectors of the region;

- the ratio of the average annual input of installed capacity and reconstruction of regional power stations over the last 5-year period to the installed capacity of the region.

Methods for calculating the indicators listed above and the procedure for reaching the integral assessment of the situation with ensuring energy security in the region are presented in the above-mentioned methodology.

\section{The situation with the provision of electricity safety of Azerbaijan}

As was shown above, in the Republic of Azerbaijan all the needs for basic energy resources are provided from domestic sources, and therefore the task of ensuring energy security is transformed into the task of ensuring electrical energy security, and because of the scale of the territory of the Republic of Azerbaijan, the regional study of energy security countries [6]. Based on the above, the composition of the indicators for the study of the energy security of Azerbaijan changes and they are presented below [7]:

- the ratio of the total available power of sources of electricity in the region to the maximum electrical load of consumers in its territory;

- the ratio of the sum of the available power of power plants and the capacity of intersystem connections to the maximum electrical load of consumers;

- the share of the largest power plant in the installed electrical capacity of the country;

- degree of depreciation of the production assets of the country's power industry;

- the ratio of the average annual input of installed capacity and the reconstruction of the country's power plants over the last 5-year period to the installed capacity of the country;

- the share of alternative and renewable energy sources in meeting the need for electricity.

Before assessing electricity security through the selected indicators, it should be noted that, as in the case of meeting the needs for major energy resources, Azerbaijan is fully provided with electricity from domestic sources of electricity. Azerbaijan also exports electricity to the electricity markets of Georgia and Turkey, as well as supplies electricity to Iran in the island mode.

The structure of the power system of Azerbaijan is such that significant generating capacity is located in the western part of the country, and the main consumers in the eastern regions of the country, where the level of imported electricity reaches $40 \%$, and therefore there are some problems with the first indicator, although due to high-voltage power lines (330 and $500 \mathrm{kV}$ ), connecting the eastern and western parts of the country, the situation on this indicator can be taken as acceptable. 
Azerbaijan satisfies both domestic electricity demand and peak power at the expense of domestic sources and therefore the assessment of this indicator can be taken as normal.

The largest power station in the Azerbaijan energy system is Azerbaijan's thermal power plant with an installed capacity of 2,400 MW, which is $38 \%$ with a total installed capacity of 6,400 MW of the Azerbaijan energy system. The status of this indicator can be considered pre-crisis, although with the commissioning of new power plants (by the end of this year, the commissioning of the Shimal-2 power station with a capacity of $409 \mathrm{MW}$ is expected) the state of this indicator will somewhat improve.

The degree of deterioration of the main production assets of the country's electric power industry is also mainly associated with the above-mentioned power station, the Azerbaijan Thermal Power Plant was built in the eighties of the last century and is to be dismantled in the near future. The degree of depreciation of the main production assets of the power industry is about $38 \%$ and the accelerated rate of renewal of generating capacity will improve the condition of this indicator, today its condition is normal-precrisis.

Over the last 5-year period, more than $800 \mathrm{MW}$ of capacity has been commissioned in the Azerbaijan energy system, which is about $12.5 \%$ of the installed capacity of the country.

At present, the share of renewable energy in meeting the country's need for electricity is about $7 \%$, and this figure is far from the target values indicated in various documents adopted in the Republic of Azerbaijan. The policy on the widespread use of renewable energy sources allows us to accept the status of this indicator as acceptable.

Integral assessment of the situation with ensuring the electricity security of Azerbaijan is characterized as acceptable.

\section{The situation with energy security of the Caspian regions of Russia}

The situation with ensuring energy security in the Caspian regions of Russia was assessed taking into account the main provisions of the above methodology. The Caspian region of Russia includes three subjects of the Russian Federation - the Astrakhan region, the Republic of Kalmykia and the Republic of Dagestan. Below, the results of the analysis will be briefly presented in turn for each of these regions.

Astrakhan region. The maximum electrical load here can be ensured by its own electricity generating sources. It is provided with a sufficient margin due to the use of intersystem electrical connections with energy-rich regions. During the analysed period (five years), the available capacity of the regional power plants increased from $572 \mathrm{MW}$ to $740 \mathrm{MW}$ with a slightly increased maximum electrical load. In total, over 5 years, $330 \mathrm{MW}$ of electrical capacity was introduced.

Opportunities to cover the primary energy needs of the region are within acceptable limits with a considerable margin due to the production of sufficient volumes of natural gas in its territory. Under these conditions, a high proportion of natural gas dominance in the balance of primary energy consumption can be considered acceptable. The indicator of the share of the largest source in power generation is located in the region of pre-crisis values and is $51 \%$, having decreased over the past five years from the crisis $65 \%$ due to the commissioning of new electricity generating facilities.

Indicators of opportunities to meet the peak of the growing demand for primary energy in the conditions of cooling in the federal district in the Astrakhan region are in the region of acceptable values of the corresponding indicator and indicate that such demand can be covered with an adequate margin.

The situation with the deterioration of the production assets of energy in the region has a steady tendency to improvement. At the same time, the depreciation of the production assets of the power industry today makes up $45 \%$ and is so far characterized as pre-crisis. At the same time, the pace of renewal of the electric power industry in the region is sufficient to characterize the situation on this indicator as acceptable.

The integral assessment of the situation with ensuring the energy security of the Astrakhan Region is characterized as acceptable ( $80 \%$ of the sum of the weights of the most important indicators of the regional level are in the zone of acceptable states).

Republic of Kalmykia. The Republic is characterized by insufficient share of its own power generation. The maximum electrical load on the territory of the republic can be covered only by $22 \%$ at the expense of its own power generating capacities. At the same time, this load with sufficient margin can be covered when using intersystem electric connections with energy-rich territories.

Only by $20 \%$ of the republic's demand for primary energy can be satisfied from its own sources (insignificant gas production) with gas dominating in the balance of primary energy consumption of about $98 \%$. Such a situation can certainly be considered a crisis. The share of the Elista gas-turbine CHPP dominant in the republic is $95 \%$, which is very dangerous in case of its emergency failure, this situation can also be considered a crisis. Depreciation of energy production assets in the republic exceeded $50 \%$ and from the standpoint of energy security is considered to be a crisis, while there is a tendency of further aging of these production assets. The same can be said about the situation with the renewal of electric power industry.

On the basis of the fact that $56 \%$ of the sum of the specific weights of the most important indicators of Kalmykia are in the zone of crisis conditions, the integral assessment of the state of energy security of the Republic of Kalmykia can be described as a crisis.

The Republic of Dagestan. In the republic, the maximum electrical load is covered with a sufficient margin. Natural gas is produced in sufficient quantities to meet the republic's own primary energy needs. According to these indicators, the situation with ensuring energy security in Dagestan is characterized as acceptable. At the same time, the $96 \%$ share of natural 
gas dominance from the standpoint of the region's energy security is extremely high and can be considered a crisis. The largest electricity generating source in the republic is the Chirkey hydropower station with a disposable capacity of $1000 \mathrm{MW}$, which is $52 \%$ of the total capacity of the republic. This indicator characterizes the pre-crisis state of the corresponding indicator. Opportunities to meet the peak increasing demand for primary energy in conditions of cooling in the federal district in the country are in the region of acceptable values of the corresponding indicator and can meet the demand for fuel in these conditions with an adequate margin.

Over the past five years, a tendency has emerged in the republic for the aging of energy production assets (depreciation of production assets amounted to about $54 \%$ ), which is characterized as a crisis indicator. The rates of renewal of the electric power industry, which have been at a pre-crisis level in recent years, are also low. In general, the integral assessment of the energy security of the Republic of Dagestan is characterized as pre-crisis (more than $46 \%$ of the sum of the weights of the most important indicators of the regional level are in the zones of crisis and pre-crisis conditions).

In general, even in the Astrakhan region, where the situation with ensuring energy security is characterized as acceptable, for individual indicators it can be seen in which direction and in what scale measures should be taken to improve the situation. In the republics of Kalmykia and Dagestan, where the situation with ensuring energy security is far from acceptable, such measures for each relevant indicator should be even more intense. The uncompensated aging of the production assets of energy is a common problem for all.

\section{Conclusion}

First of all, it should be noted that the approach to analyzing the situation with ensuring energy security may be similar for the regions of Russia and Azerbaijan. At the same time, the influence of the Caspian regions of the two countries on ensuring the energy security of these countries is significantly different. If for Azerbaijan this influence is largely decisive, then for Russia it is not too significant. Thus, in this case, the problems of ensuring the energy security of the Caspian regions themselves come out on top. At the same time, the main efforts should be directed at minimizing the problem moments of organizing the fuel and power supply of these regions, identified in the process of an indicative analysis of energy security at the regional level. As for Azerbaijan, a comprehensive analysis of the scale of implementation of the most significant threats to the energy security of the Caspian region showed that the level of energy security of this region and the country as a whole is determined by the situation with the development and functioning of the oil and gas sector in the region.

Taking into account the above, among the emerging negative trends, first of all, it should be pointed out that the export volume in the current decade has decreased from the oil and gas sector of the Caspian region of Azerbaijan. For the long-term perspective (over 15 years), this tendency, apparently, cannot be considered negative - especially if the proportion of non-energyintensive, knowledge-intensive sectors of the state's economy increases with a decrease in oil and gas exports.

As for Russia, the analysis of the state of energy security is shown in the article for the Caspian regions. From such assessments and follows the main focus of action to implement the necessary steps to normalize the situation.

The work was carried out within the framework of a scientific project III.17.5.1 of program of fundamental research of the SB RAS, reg. number AAAA-A17-117030310451-0.

This work was supported by the Science Development Foundation under the President of the Republic of Azerbaijan Grant № EİF-BGM-4-RFTF-1/2017-21/09/1.

\section{References}

1. Energy of Azerbaijan. Problems and prospects for the development of the energy sector of the Republic of Azerbaijan / http://matveev-igor.ru/articles/366220.

2. Opening speech by Ilham Aliyev at a meeting of the Cabinet of Ministers dedicated to the results of socioeconomic development in the first half of 2018 and the upcoming tasks / https://ru.president.az/articles/29539

3. "The Contract of the Century" 20 years later: an indisputable benefit https://www.bbc.com/Russian /business/2014/09/140919_azerbaijan_century_oil_contr act_anniversary.

4. State Statistical Committee of the Republic of Azerbaijan. Azerbaijan in Figures, 2016 /http://istmat.info/files/uploads/53204/azerbaijan_in_figu res_2016.pdf.

5. S.M. Senderov, N.I. Pyatkova, V.I. Rabchuk et al. Methods of monitoring the state of Russia's energy security at the regional level. Irkutsk: ISEM SB RAS, 2014. - 164 p.

6. Yusifbeyli N.A., Nasibov V.Kh. Models of the study of the electricity security of Azerbaijan . Moscow: Institute of Energy Strategy, scientific, social and business magazine Energy Policy №3, 2013. - p. 50-59.

7. Nasibov V.Kh. Determination of Azerbaijan electric power industry security for long-term periods on the basis of fuzzy deduction. Berlin: Journal of Multidisciplinary Engineering Science Studies (JMESS), Vol. 2 Issue 3, March, 2016. - pp. 363-373. 